\title{
Einladung zur Mitgliederversammlung der DRG am Donnerstag, den 25. Mai 2017
}

Zur ordentlichen Mitgliederversammlung der Deutschen Röntgengesellschaft Gesellschaft für Medizinische Radiologie e. V. (DRG), am Donnerstag, den 25. Mai 2017, von 17:30 - 19:30 Uhr im Congress Centrum Leipzig (CCL) im Raum Röntgen, lädt der Vorstand der DRG die Mitglieder der DRG hiermit herzlich ein.

\section{Tagesordnung}

- TOP 1: Begrüßung

- TOP 2: Totengedenken

- TOP 3: Genehmigung des Protokolls der Mitgliederversammlung vom 5. Mai 2016 (veröffentlicht im Jahresbericht 65, Januar 2017)

- TOP 4: Bericht des Präsidenten

- TOP 5: Bericht des Schatzmeisters
- TOP 6: Bericht der Kassenprüfer

- TOP 7: Entlastung des Vorstandes

- TOP 8: Vorschläge für Ehrungen 2018

- TOP 9: Wahl der Kassenprüfer 2018

- TOP 10: Wahl des Vorstandes für die Amtsperiode Röntgenkongress 2017 2019

- TOP 11: Wahl des Präsidenten für die Amtsperiode Röntgenkongress 2019 2021

- TOP 12: Wahl des Kongresspräsidenten 2020

- TOP 13: Bericht der Akademie für Fortund Weiterbildung in der Radiologie

- TOP 14: Bericht des Vorsitzenden der Vereinigung der Medizinisch-Technischen Berufe in der DRG (VMTB)

- TOP 15: Bericht des Justitiars der DRG
- TOP 16: Einladung zum Röntgenkongress 2018

- TOP 17: Verschiedenes

Die Einlasskontrolle erfolgt über den Kongressausweis. Entsprechend der Satzung der DRG können an der Mitgliederversammlung nur Mitglieder teilnehmen, deren Beitragskonto für 2017 ausgeglichen ist.

\section{Im Namen des Vorstandes}

Prof. Dr. Dierk Vorwerk (Präsident) 